\title{
InfoGrid: Information Resource Integration
}

\author{
Nikolaos Giannadakis, Mustafa Ghanem, and Y. Guo \\ Imperial College London \\ $\{\mathrm{ng} 300, \mathrm{mmg}, \mathrm{yg}\}$ adoc.ic.ac.uk
}

Grid computing [3] constitutes the amalgamation of a drive towards the standardization of existing technologies that enable the collaboration of scientists overcoming restrictions of location, distance and compatibility. The aim is to exploit the full potential of resources, computational or informational. We aim to study how a network of distributed and heterogeneous grid resources could attain maximum adaptability to languages, models, scientific uses in a service composition based knowledge discovery environment. No language or data model assumptions are herein made. The presence of grid layers that can handle basic service registration, etc. tasks, service execution and data mobility is premised.

Accordingly, no assumption is made about the nature of the information that grid resources need to communicate. Emphasizing on the composing aspect, we move complexity from the query engine to the composition level by means of utilizing component (Grid Service) composition languages, composing service-based data resources. Service composition now becomes an information resource static integration tool.

The composed information services are essentially composed grid services and hence able to utilize all other available grid services. We assert that that execution logic of such composed programs should be enriched with logic for the provision of metadata. No assumptions should either be made for the type of metadata. Integration languages (distributed query languages) on top of the middleware can have their own requirements. A composed service will simply declare its supported languages or standards. Additional components will be created facilitating and being specialized for information resource composition.

Finally, a dynamic integration layer is proposed whereby an arbitrary integration language can declare its model and grid services which will transform a query expressed in it into a composite service that can be executed and return any results. Any such decomposing grid services will be mapping their operators to the corresponding grid services and ditto with any direct references to other resources.

From an information access point, our contribution is the proposed use of service composition and invocation layers as a means of integration with no language or model prerequisite. From a service composition view, we propose the introduction of dynamic metadata logic for services, built on top of existent composition capabilities. We aim to demonstrate that this approach can reproduce the integration capabilities of other approaches and, furthermore, that it is able to accommodate more complicated integration needs.

We are designing InfoGrid (the information integration effort of Imperial College's DiscoveryNet [4] project) which has the goal of addressing the needs of the scientific 
community. In particular, bioinformatics and chemistry applications will constitute the application domains of our research.

Table 1. An overview of the resource characteristics for the basic information access approaches and that of InfoGrid.

\begin{tabular}{|c|c|c|c|c|}
\hline \multicolumn{5}{|l|}{ Resources } \\
\hline & JDBC resource & Discovery Link & OGSA-DAI & InfoGrid \\
\hline $\begin{array}{l}\text { Metadata } \\
\text { language }\end{array}$ & $\begin{array}{l}\text { Relational Db connec- } \\
\text { tion information }\end{array}$ & \multirow{2}{*}{$\begin{array}{l}\text { Special wrappers have to } \\
\text { be available/ metadata is } \\
\text { set statically during } \\
\text { registration }\end{array}$} & $\begin{array}{l}\text { Available } \\
\text { through a Web } \\
\text { Service interface }\end{array}$ & Any \\
\hline $\begin{array}{l}\text { Metadata } \\
\text { model }\end{array}$ & $\begin{array}{l}\text { A DatabaseMetaData } \\
\text { Java object }\end{array}$ & & XML Schema & Any \\
\hline $\begin{array}{l}\text { Invocation } \\
\text { language }\end{array}$ & SQL & \multirow[t]{2}{*}{$\begin{array}{l}\text { Handled internally by } \\
\text { precompiled wrappers }\end{array}$} & SQL or XQuery & Any \\
\hline Results model & A ResultSet object & & $\begin{array}{l}\text { Files (Tables or } \\
\text { XML) }\end{array}$ & Any \\
\hline
\end{tabular}

Table 2. A summary of the integration approaches. We aim to prove that InfoGrid can reproduce all these.

\begin{tabular}{|l|l|l|l|l|}
\hline Integration Approaches & JDBC & $\begin{array}{l}\text { DiscoveryLink } \\
{[1]}\end{array}$ & OGSA-DAI [2] & Query Based \\
\hline Type & Bespoke & Federation & $\begin{array}{l}\text { Static \& query based } \\
\text { using the composition } \\
\text { layer }\end{array}$ \\
\hline Metadata & $\begin{array}{l}\text { N/A (individ- } \\
\text { ual relational } \\
\text { models }\end{array}$ & $\begin{array}{l}\text { Common Static } \\
\text { Relational } \\
\text { Model }\end{array}$ & $\begin{array}{l}\text { Individual XML or } \\
\text { relational models } \\
\text { expressed in XML } \\
\text { Schema }\end{array}$ & $\begin{array}{l}\text { Metadata independent } \\
\text { Using the }\end{array}$ \\
\hline Language & SQL & SQL & OQL & $\begin{array}{l}\text { For query based } \\
\text { integration all lan- } \\
\text { guages that provide a } \\
\text { decomposing service }\end{array}$ \\
\hline Invocation & Orchestration & Abstracted & $\begin{array}{l}\text { Decomposition into } \\
\text { execution primitives } \\
\text { with the aid of a } \\
\text { service dictionary. }\end{array}$ & Grid execution layer \\
\hline
\end{tabular}

\section{References}

[1] Discovery link from IBM

[2] Open Grid Services Architecture Data Access and Integration (http://www.ogsadai.org.uk/)

[3] Global Grid Forum (http://www.gridforum.org/)

[4] DiscoveryNet project (http://ex.doc.ic.ac.uk/new/) 